\title{
Unusual applications of oxygen heterocycles in synthesis
}

\author{
Carl R. Johnson \\ Wayne State University, Department of Chemistry \\ Detroit, Michigan 48202, U.S.A.
}

\begin{abstract}
A program underway in the author's lab to examine the production and synthetic utility of 1,2-hydroxycycloalkanones and derivatives is described. Emphasis is placed on the synthesis of optically pure, biologically active, natural products.
\end{abstract}

\section{THE SULFOXIMINE ROUTE}

Compound $\mathbf{1}$ is rapidly deprotonated with butyllithium in tetrahydrofuran to provide $\underline{\mathbf{N}}-$ methylphenylsulfonimidoylmethyllithium (2). Additions of optically pure 1 (as the lithio reagent 2) to a simple acyclic prochiral ketone or aldehyde results in the production of two optically active diastereomeric adducts 3.1 We have found these $\beta$-hydroxysulfoximines (3) are thermally unstable and revert to the starting carbonyl compound and sulfoximine in the temperature range of 80 to $120^{\circ} \mathrm{C} .1 \mathrm{~b}$ The reversion is probably facilitated by the transfer of the $\mathrm{OH}$ proton to the sulfoximine nitrogen such that carboncarbon bond cleavage occurs with the ylide 4 as the leaving group. The ylide selfquenches by tautomerization to the starting sulfoximine (Scheme 1). One might envision the overall procedure of adduct formation and thermal release of the starting materials as a carbonylprotection/deprotection procedure. The deprotection step is especially intriguing in that it occurs without the intervention of acid or base.

\section{Scheme :}

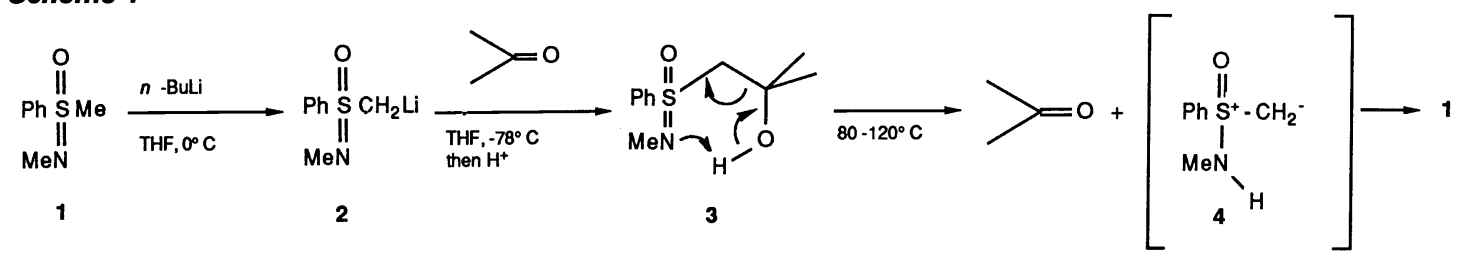

The addition of optically pure 1 as the lithio reagent 2 to prochiral enones, or the diastereoface-selective addition to racemic chiral enones, results in the formation of two optically active diastereomeric adducts, e.g., 5 and 6 (Scheme 2). In such adducts we envisioned that the hydroxyl group and/or the sulfoximine nitrogen might serve to control diastereoface selectivity in addition reactions to the remaining carbon-carbon double bond. Combining this diastereoface selectivity of the addition with a subsequent thermal reversion of the sulfoximine addition would result, in effect, in enantiofacecontrolled additions to the carbon-carbon double bond of the original enone (Scheme 2). For our first test of this concept, the Simmons-Smith cyclopropanation reaction was chosen as it has been well documented to be directed by oxygen coordination.

Treatment of the individual diastereomeric isophorone/sulfoximine adducts 7 with diiodomethane $/ \mathrm{Zn}(\mathrm{Ag})$ in refluxing diethyl ether followed by thermolysis resulted in the enantiomeric cyclopropyl ketones 8 with $[\alpha]^{25}+160.6^{\circ}$ and $-164^{\circ}$ (Scheme 3). This methodology has been applied to the synthesis of $(-)$ - and (+)-thujopsene (9), $2(-)$ rothrockene $(10)^{3}$ and a variety of other optically pure cyclopropyl ketones. ${ }^{2}$ 


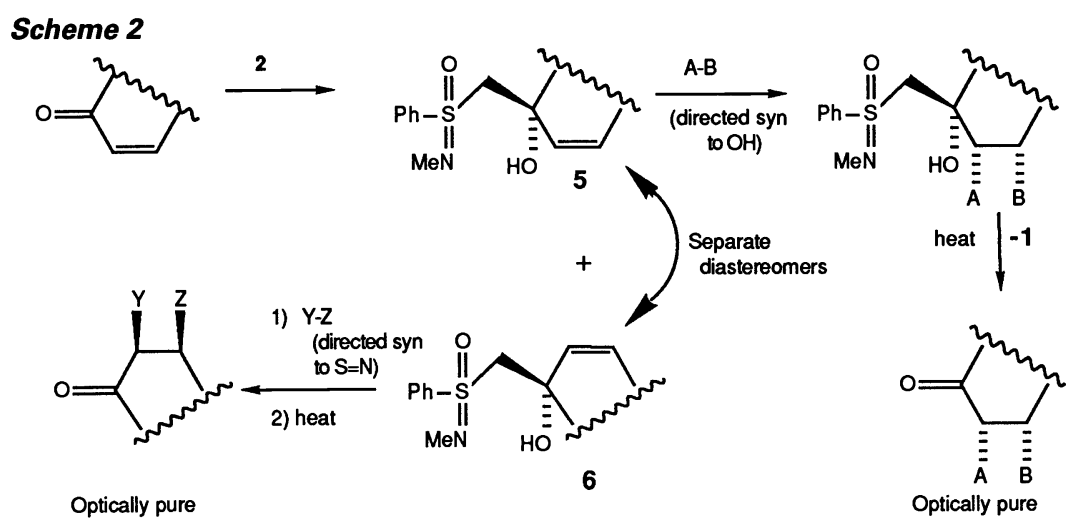

Scheme 3<smiles>CC1=CC(=O)CC(C)(C)C1</smiles><smiles>CC1=CCC2(C)CCCC(C)(C)C23CC13</smiles>

9<smiles>CC1=C[C@](O)(CS(=O)(=O)c2ccccc2)CC(C)(C)C1</smiles>

7

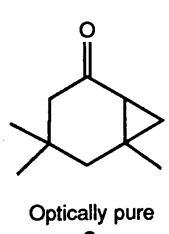

8

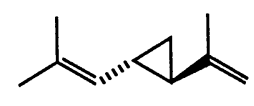

10

Scheme 4

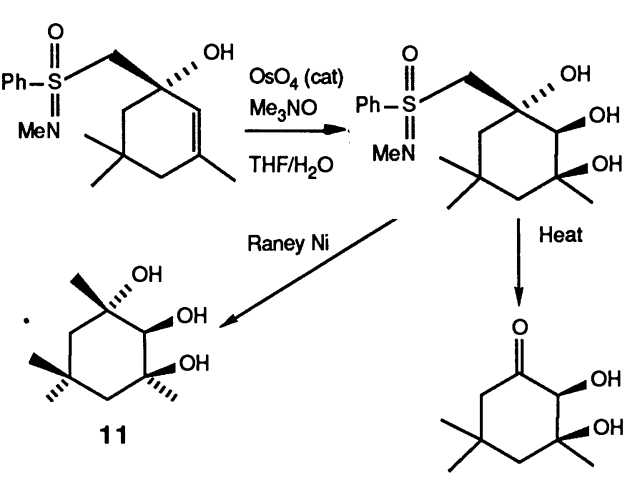

$[\alpha]_{\mathrm{D}} 25-29.3^{\circ}$

Osmium tetroxide is known to form addducts reversibly with basic ligands such as pyridine and quinuclidine. We anticipated that the methylimino group of sulfoximines such as $\mathbf{5}$ and $\mathbf{6}$ would provide, by "chelation control," diastereoface selection in the osmylation of the adjacent carbon-carbon double bond. Furthermore, the "antiperiplanar" effect 4 of the allylic hydroxyl group should provide a synergitic enhancement of the diastereoface selectivity. The overall result would be a novel optical activation method involving directed osmylation and thermal reversal of the sulfoximine addition to afford optically pure dihydroxycycloalkanones and the recyclable resolving agent 1. Again, the optically pure adducts of isophorone and 1 were chosen for initial study (Scheme 4). 5 Treatment of the individual diastereomers in water/THF solutions containing trimethylamine $\mathrm{N}$-oxide dihydrate ( 1.5 equiv.) with solutions of osmium tetroxide $(5 \mathrm{~mol} . \%)^{6}$ in THF afforded, in each case, a single triol. Desulfurization of each triol provided a material which exhibited ten resonances in the decoupled ${ }^{13} \mathrm{C}$ NMR spectrum and four methyl singlets in the $1_{H}$ NMR spectrum, consistent with the unsymmetrical structure 11. The optically active cis-hydroxylated sulfoximine adducts undergo clean thermal elimination of the sulfoximine in refluxing solvent (2-butanol, toluene, or xylene) to provide optically pure dihydroxycycloalkanones. A selection of compounds prepared by this technique is shown in Scheme 5 . Of particular note are the successes obtained with a 3-cyclohexenone substrate (homoallylic oxidation) and the cyclopentenone substrate. In the latter case, preparation of the diols shown represent

Scheme 5<smiles>CC1(C)CC(=O)[C@H](O)[C@H](O)C1</smiles><smiles>C[C@]1(O)C(=O)CCC[C@@H]1O</smiles><smiles>CCCCO[C@@]1(O)C(=O)CCC[C@H]1O</smiles><smiles>CCCCOC[C@]1(O)C(=O)CC[C@@H]1O</smiles> 
formal total syntheses of both optical isomers of the antibiotics pentenomycin I and II since Smith and co-workers 7 have successfully converted racemic material to these substances. To date, attempts to extend this oxidation methodology to the preparation of enantiomerically pure acyclic diol ketones have not been successful.

\section{THE ENZYME ROUTE}

The successes described above the production of optically pure dihydroxy cycloalkanones and derivatives has prompted an interest in our labs in exploring the chemistry, in general, of this class of substances particularly with respect to utilization as chiral synthons for the production of optically pure natural products. Our first efforts were directed towards the synthesis of prostanoids, particularly of the PGE class, e.g., $\mathrm{PGE}_{2}$ (12).

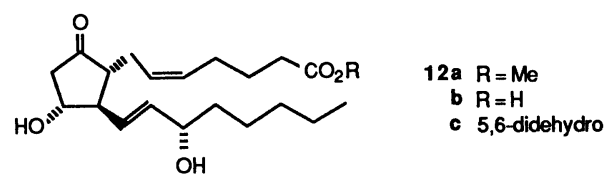

A straight-forward triply convergent approach to the synthesis of $\mathrm{PGE}_{2}$ and related substances has been a long sought goal.8,9 The problem with this approach is that under conditions conducive to alkylation equilibration to the enolate occurs followed by elimination of the protected 4-hydroxy group (Scheme 6) to provide the undesired enone 13 as the major product.

It appeared to us that enone 14 would be an ideal substrate for this three-component coupling process. We postulated that the presence of the $\alpha$-oxygen functionality constrained in the five-membered ring would suppress enolate equilibration (by a combination of charge repulsion and angle strain (double bond exo to a five-membered ring in the unfavored enolate) and alkylation would occur regiospecifically to afford the trans vicinally dialkylated product. Reductive removal of the $\alpha$-oxygen group would yield the PGE structural system (Scheme 7).

\section{Scheme 6}<smiles>O=C(O)C1=CC([18O])CC1=O</smiles><smiles>[R]C1C=C(OC)CC1[R6]</smiles><smiles>[2H][C@H]1CC(=O)[C@H]([2H])[C@@H]1P</smiles>

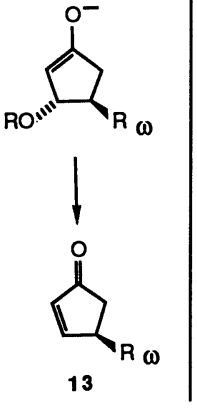

\section{Scheme 7}

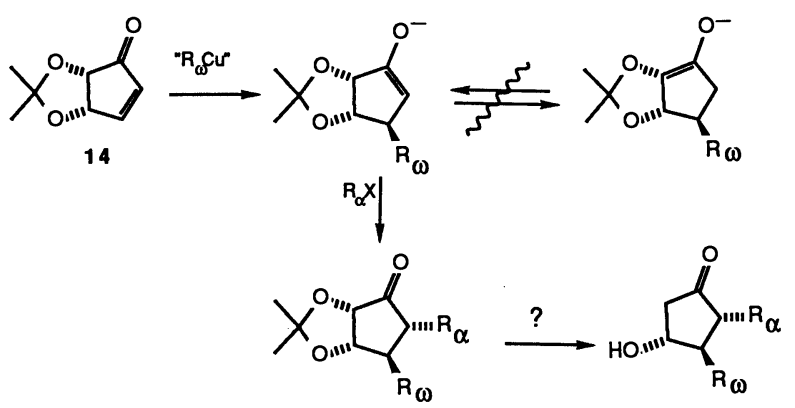

Enone 14 was synthesized in six steps (40\% overall yield) from cyclopentadiene as shown in Scheme 8. Optical resolution 1 a of 14 was achieved with $(+)-N, S$-dimethyl-Sphenylsulfoximine (1) to afford $(+)-14$, and $(-)-14$. On the basis of a comparative ORD study with (-)-17 (+ Cotton effect) obtained from (-)-ribose, $10(+)-14$ (- Cotton effect) was assigned the 10S, 11S (PG numbering) absolute stereochemistry.

Scheme 8

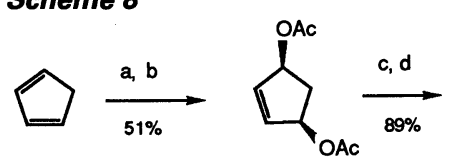

15

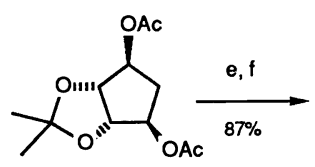

16

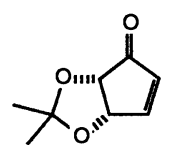

14

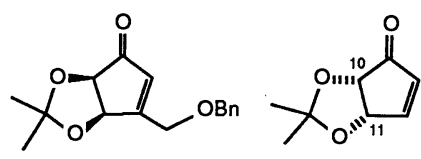

$(-)-17$

${ }^{2} \mathrm{O}_{2}$, hv, rose bengal, thiourea, $\mathrm{MeOH} ;{ }^{b} \mathrm{Ac}_{2} \mathrm{O} ;{ }^{c} \mathrm{OsO}_{4}$ (cat), $\mathrm{Me}_{3} \mathrm{NO} ;{ }^{d}$ Acetone, $\mathrm{H}^{+} ;{ }^{e}$ aq $\mathrm{KOH} ;{ }^{f} \mathrm{DMSO}, \mathrm{DCC}$, pyr., TFA. 
Although the sulfoximine-based resolution sequence outlined above served us quite well, the method suffers from the inherent $50 \%$ maxim material balance problem of a resolution. We therefore sought a method for the production of $(+)-14$ based on asymmeric synthesis. On the basis of earlier studies on enzymatic differentiation of the acetates of meso-15, 11 we examined a number of esterase-catalyzed hydrolyses of meso16. Success was variable until our attention was drawn to electric eel acetylcholinesterase by a recent report on the asymmetric hydrolysis of 15.12 Treatment of 16 in aqueous suspension with electric eel acetylcholinesterase (ca. $1 \mathrm{mg}$ of enzyme/g of 14) provided monoacetate 18 (80\%) which was oxidized with Jones reagent to enone (+)-14 (95\%) (Scheme 9).

Scheme 9

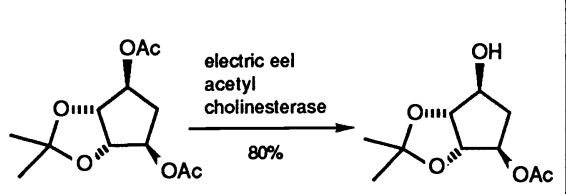

16<smiles>CC1(C)O[C@H]2C=CC(=O)[C@H]2O1</smiles>

(98\% ee)

$(+)-14$

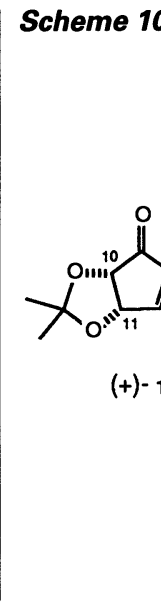

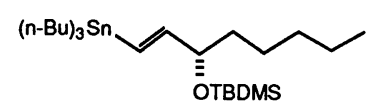

ÖTBDMS

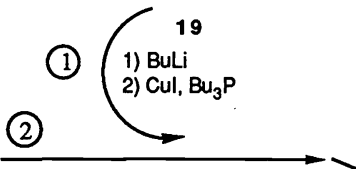

(53\%)

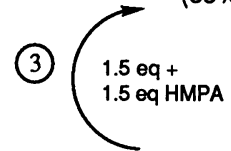<smiles>CCCCC[C@H](O)C=C[C@@H]1[C@H](CC=CCCCOC)C(=O)[C@@H]2OC(C)(C)O[C@@H]21</smiles>

OR

$\left.\begin{array}{rl}\text { 21a } & R=T B D M S \\ \text { b } & R=H\end{array}\right) H F$, Pyr. (90\%)

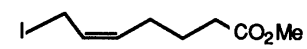

20

A phosphine-stabilized organocopper reagent was prepared from 19. Addition of this copper reagent ( 1.1 equiv) to $(+)-14$ at $-78^{\circ} \mathrm{C}$, followed by direct alkylation of the resulting enolate with iodide 20 ( 1.5 equiv) in the presence of HMPA ( 2.0 equiv) at $-30^{\circ}$ $\mathrm{C}$ for $3 \mathrm{~h}$, resulted in a $53 \%$ yield of the trans vicinally disubstituted product $21 \mathrm{a}$ (Scheme 10). Desilylation with aqueous $\mathrm{HF}$ and pyridine in acetonitrile yielded 21b in $89 \%$ yield.

With the production of $21 \mathrm{a}$, the complete, optically pure $\mathrm{PGE}_{2}$ skeleton was in hand. It only remained to unveil $\mathrm{PGE}_{2}$ by deprotection of the diol and excision of the now superfluous oxygen at $\mathrm{C}-10$. It appeared to us that this unveiling operation could be achieved in a single step by use of dissolving metal reagents (Scheme 11).

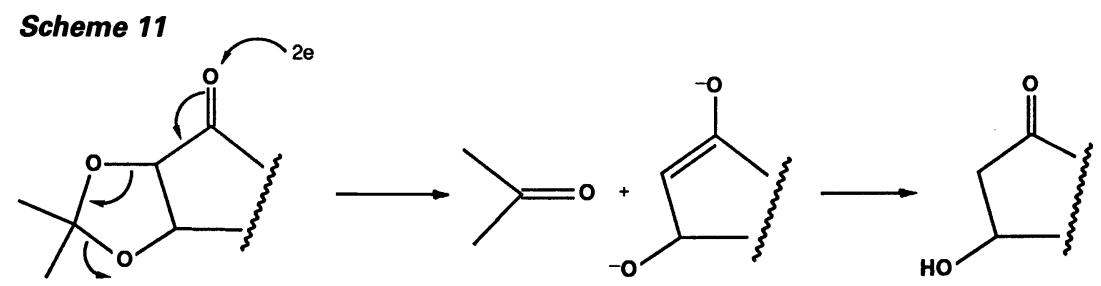

Reduction of $21 \mathrm{~b}$ with $\mathrm{Al}(\mathrm{Hg})$ in aqueous THF furnished (-)-PGE 2 methyl ester (12), $[\alpha]^{20} \mathrm{D}-78.8^{\circ}$ (c $\left.1.25, \mathrm{MeOH}\right)\left[\right.$ lit. $\left.\left.[\alpha]^{20} \mathrm{D}-71.7^{\circ}(c) .04 \mathrm{MeOH}\right)\right]$, in $98 \%$ yield (Scheme 12); no diastereomers of 12 could be detected by high-field $1_{\mathrm{H}}$ or ${ }^{13} \mathrm{C}$ NMR of the

Scheme 12
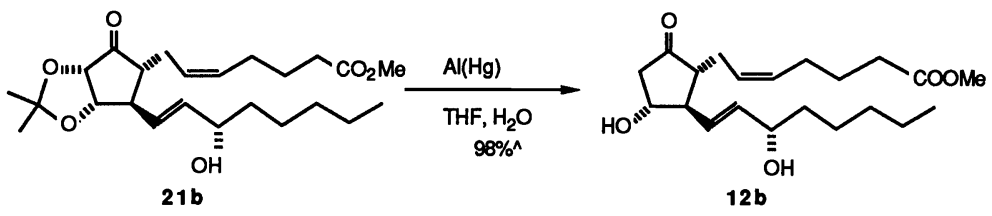
product. Ester 12 has previously been converted to (-)-PGE 2 by enzymatic ester hydrolysis. The 5,6-didehydro analogue (12c) of $\mathrm{PGE}_{2}$ was also synthesized in racemic form in a similar manner in $51 \%$ overall yield. 13

Two aspects of the above chemistry have captured our attention. First, the concept of using a protected (e.g., acetonide) $\alpha, \beta$-dihydroxy ketone as a surrogate for the acid and base sensitive aldol functionality during a complex molecule synthesis should be widely applicable: Second, the enone (+)-14 should be a useful synthon for the production of a variety of optically pure targets. We call the readers attention to the matters that the core of the synthon contains five carbons, each is functionalized and differentiated in reactivity. Furthermore, the molecule is readily available, enantiomerically pure, and its envelope-shaped structure leads to complete diastereoface differentiation in many reactions.

One possibility is the production of carbocyclic nucleosides from synthon 14. A retrosynthetic analysis of the interesting, antitumor agent neplanocin A (22) as illustrated in Scheme 13.

Scheme 13

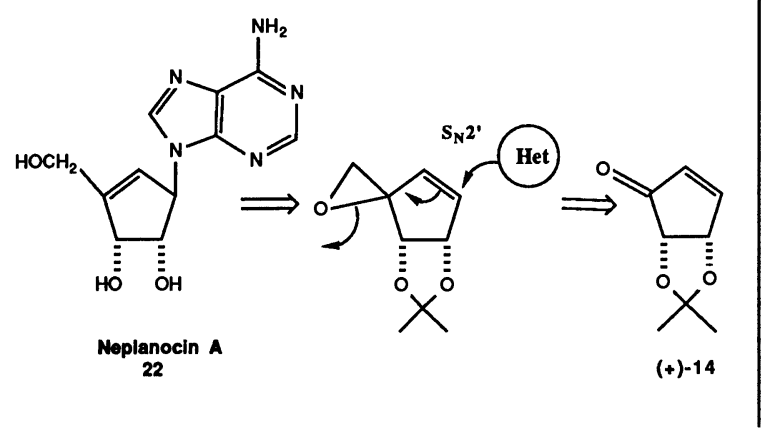

Scheme 14

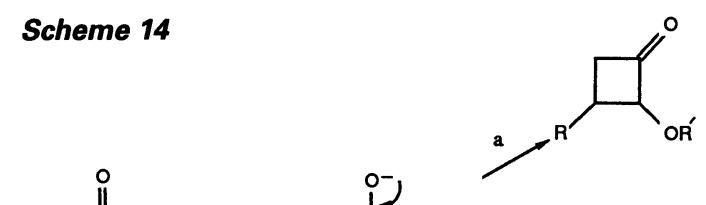

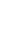




\section{Scheme 16}

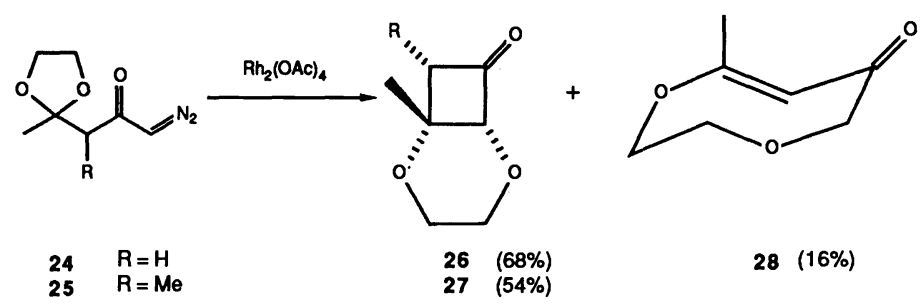

Acknowledgement The chemistry herein described was the result of contributions from the following coworkers: Dr. Michael Barbachyn, Dr. Kevin Kunen, Dr. Thomas Penning, Mr. Yung-fa Chen, Mr. John Medich, Dr. Bogdan Bujnicki, Dr. Hidemi Yoda, and Dr. Eric Roskamp. The work has been supported by grants from the National Science Foundation and the National Institutes of Health.

\section{REFERENCES}

1. (a) Johnson, C. R.; Kirchhoff, R. A. J. Am. Chem. Soc. 1979, 101, 3602; (b) Johnson, C. R.; Zeller, J. R. Tetrahedron 1984, 40, 1225.

2. Johnson, C. R.; Barbachyn, M. R. J. Am. Chem. Soc. 1982, 104, 4290.

3. Barbachyn, M. R.; Johnson, C. R.; Glick, M. D. J. Org. Chem. 1984, 49, 2746.

4. For discussions of the "anti-periplanar effect" and its role in controlling the stereochemistry of additions to allylic systems, see: Carmella, P.; Rondan, N. G.; Paddon-Row, M. N.; Houk, K. N. J. Am. Chem. Soc. 1981, 103, 2438 and additional references cited in reference 5 .

5. Johnson, C. R.; Barbachyn, M. R. J. Am. Chem. Soc. 1984, 106, 2459.

6. Van Rheenen, V.; Kelly, R. C.; Cha, D. Y. Tetrahedron Lett. 1976, 17, 1973; Ray, R.; Matteson, D. S. ibid 1980, 21449.

7. Smith, A. B., III; Branca, S. J.; Pilla, N. N.; Guaciara, M. A. J. Org. Chem. 1982, 47, 1855.

8. For a review, see: Noyori, R.; Suzuki, M. Angew. Chem., Int. Ed., Engl. 1984, 23, 847.

9. For other solutions to this problem, see Suzuki, M.; Yanagisawa, A.; Noyori, R. J. Am. Chem. Soc. 1985, 107, 3348 and Corey, E. J.; Nimura, K.; Konishi, Y.; Hashimoto, S.; Hamada, Y. Tetrahedron Lett. 1986, 27, 2199.

10. Lim, M. I.; Marquez, V. E. Tetrahedron Lett. 1983, 24, 5559.

11. For example, see: Miura, S.; Kurozumi, S.; Toru, T.; Tanaka, T.; Kobayashi, M.; Matsubara, S.; Ishimoto, S. Tetrahedron 1976, 32, 1893; Laumen, K.; Schneider, M. Tetrahedron Lett. 1984, 25, 5875.

12. Deardorff, D. R.; Matthews, A. J.; McMeekin, D. S.; Craney, C. L. Tetrahedron Lett. 1986, 27, 1255.

13 Johnson, C. R.; Penning, T. D. J. Am. Chem. Soc. 1986, 108, 5655.

14. Johnson, C. R.; Roskamp, E. J. J. Am. Chem. Soc. 1986, 108, 6062; see also: Pirrung, M. ibid 1986, 108, 6060. 